\title{
Mutations in Bone Morphogenetic Protein Receptor Genes in Pulmonary Arterial Hypertension Patients
}

\author{
- Possible Involvement of BMPRIB - \\ Isao Shiraishi, $\mathrm{MD}, \mathrm{PhD}$
}

$\mathbf{P}$ ulmonary arterial hypertension (PAH) is a progressive and substantially fatal disease characterized by sustained elevation of pulmonary artery pressure (mean $>25 \mathrm{mmHg}$ at rest). Pathophysiological features of PAH include vascular remodeling of precapillary resistance pulmonary arteries (ie, dysfunction of endothelial cells, activation and proliferation of smooth muscle cells, and fibrous infiltration into the arterial wall). These processes give rise to marked vasoconstriction and obstructive or plexiform changes of the small pulmonary arteries. ${ }^{1}$

\section{Article p 1501}

According to the updated clinical classification of pulmonary hypertension (Dana Point, 2008), ${ }^{2}$ PAH is classified as: (1) idiopathic, (2) hereditable, (3) drug- or toxin-induced, (4) associated with other diseases, and (5) persistent pulmonary hypertension of the newborn. Among these, genetic disorders of bone morphogenetic protein receptor type II (BMPRII), one of the TGF- $\beta$ superfamily receptors, have been extensively studied and shown to be significant in the pathogenesis of PAH. Recent studies have clarified that mutations in BMPR2 have been identified in approximately $70 \%$ of the hereditable cases and in up to $40 \%$ of cases of idiopathic PAH. ${ }^{2}$

BMP signaling (Figure) in general regulates growth, differentiation, survival, and apoptosis in a variety of cells during embryogenesis, postnatal development, and maintenance of adult tissues. ${ }^{3-5}$ BMPRII is a constitutively active serine/threonine kinase and it initiates intracellular signaling in response to binding to the tissue specific BMP ligands. Upon binding to the ligands, BMPRII phosphorylates the glycine/serine-rich (GS-) domain on the proximal intracellular portion of associated type I receptors known as activin receptor-like kinase 1 (ALK1), BMPRIA (ALK3), or BMPRIB (ALK6). The activated type I receptors, in turn, phosphorylate downstream receptor-mediated signaling proteins (R-Smads) Smad1/5/8. After association with a common mediator Smad (Co-Smad) Smad4, the Smad1/5/8 complex translocates to the nucleus and regulates a variety of transcriptional responses in concert with nuclear cofactors and repressors. The Smad-mediated BMP signaling mainly executes pro-apoptotic properties to maintain the integrity of the vascular structure and function. In the normal small pulmonary arteries, BMPRII is highly expressed on the endothelial cell surface and, at a lower level, in smooth muscle cells and fibroblasts. In patients with $\mathrm{PAH}$, the expression of BMPRII is markedly reduced in the pulmonary arterial wall, regardless of mutations, and the phosphorylation of Smad1/5/8 is reduced as well. These findings suggest that the downregulation of both BMPRII and Smad-mediated signaling may be important in the pathogenesis of PAH. ${ }^{4,5}$

On the other hand, several Smad-independent pathways and imbalance of vascular effectors have also been shown to play a role in the onset and progression of PAH. ${ }^{4,5}$ First, BMPRII directly or indirectly activates mitogen-activated protein kinases (MAPK) such as ERK1/2, JNK, p38MAPK. The exaggerated activation of $\mathrm{p} 38 \mathrm{MAPK}$ is observed in the arterial wall of $\mathrm{PAH}$, which leads to vascular smooth muscle cell proliferation ${ }^{6}$ and implies that the p38MAPK pathways are involved in the pathogenesis of PAH. Second, reduced penetrance in hereditable $\mathrm{PAH}$ and the wide range of the age distribution of the disease suggest that imbalance of multiple vascular effectors or "second hit" elements must be involved in the onset of the disease. ${ }^{4,7}$ To date, possible factors include serotonin $(5 \mathrm{HT})$, serotonin transporters (5HTT) and receptors, platelet-derived growth factor (PDGF), epidermal growth factor (EGF), endothelin-1 (ET-1), angiopoietin-1 (Ang-1), Rho GTPases, $\left[\mathrm{Ca}^{2+}\right]$ channels, matrix metalloproteinase (MMPs), elastase, thromboxan A2 (TXA2), inflammatory reactions, nitric oxide (NO), prostacyclin, $\left[\mathrm{K}^{+}\right]$ channel, and PPAR $\gamma$, etc. The particular mechanisms of these factors in pulmonary vascular remodeling are now being extensively studied as possible therapeutic targets of PAH.

Mutations in a transforming growth factor (TGF)- $\beta$ superfamily receptor activin-like kinase-1 (ALK1) and a co-receptor endoglin (ENG), which are predominantly associated with hereditary hemorrhagic telangiectasia (HHT), have also been recognized as uncommon genetic disorder of PAH. Considering that BMP-mediated signaling is crucial in the pathogenesis of PAH, it is likely that mutations other than BMPRII, ALK1, or ENG may also be involved in pathogenesis of PAH. To date, however, mutations in a Smad protein, $\operatorname{Smad} 8$, alone have been identified as a possible cause of hereditable PAH. ${ }^{8}$

In this issue of the Journal, Chida et $\mathrm{al}^{9}$ report novel missense mutations in the BMP type I receptor protein BMPRIB (ALK6) gene in pediatric patients with PAH. Although BMPRI proteins are important partners and effectors of BMPRII and are likely to be involved in the pathogenesis of PAH, BMPRIB mutations have not been reported in $\mathrm{PAH}$ patients. The authors

The opinions expressed in this article are not necessarily those of the editors or of the Japanese Circulation Society.

Received April 22, 2012; accepted April 22, 2012; released online May 15, 2012

Department of Pediatric Cardiology, National Cerebral and Cardiovascular Center, Suita, Japan

Mailing address: Isao Shiraishi, MD, PhD, Department of Pediatric Cardiology, National Cerebral and Cardiovascular Center, 5-7-1

Fujishirodai, Suita 565-8565, Japan. E-mail: isao@ hsp.ncvc.go.jp

ISSN-1346-9843 doi:10.1253/circj.CJ-12-0534

All rights are reserved to the Japanese Circulation Society. For permissions, please e-mail: cj@j-circ.or.jp 


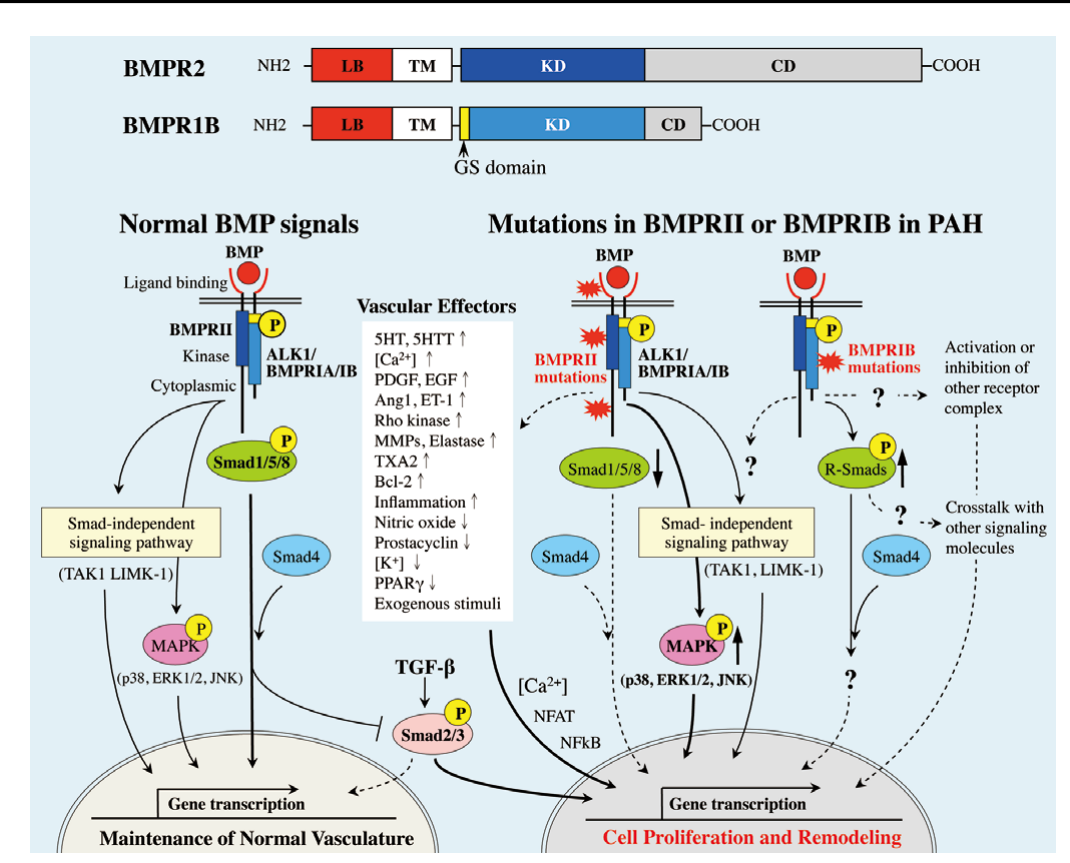

Figure. Signal transduction of bone morphogenetic protein (BMP) and its possible interaction with other molecules involved in the development of pulmonary arterial hypertension (PAH). LB, ligand binding domain; TM, transmembrane domain; KD, kinase domain; CD, cytoplasmic domain.

screened for mutation in Smad1-Smad7, BMPRIA/IB, and ENG genes in $43 \mathrm{PAH}$ patients who had no mutations in BMPRII, ALK1 or Smad8. The authors identified 2 novel missense mutations of BMPRIB (ie, $479 \mathrm{G}>\mathrm{A}$ and $1176 \mathrm{C}>\mathrm{A}$ ), which were not detected in 450 healthy controls. The mutations were located between the transmembrane- and GS-rich-domain and in the serine/threonine kinase domain, respectively.

In addition to the detection of novel BMPRIB mutations in $\mathrm{PAH}$, this study includes several interesting observations. The $B M P R I B$ mutation in the kinase domain $(1176 \mathrm{C}>\mathrm{A})$ strongly induced Smad8 phosphorylation and increased transcriptional activity in the presence of Smad8. As described earlier, BMPRII mutations in PAH diminish BMPRII protein expression and Smad1/5/8-mediated pro-apoptotic signaling of BMP. In contrast to the conventional hypothesis that the loss-of-signaling in BMPRII mutations may be a major cause of PAH, the authors propose a novel gain-of-signaling mechanism. This suggests that not only inhibition but also promotion of BMP signaling is likely to be associated with the pathogenesis of PAH. The precise molecular mechanisms remain uncertain. One report showed that the expression of BMPRIB is markedly increased in PAH smooth muscle cells not bearing BMPRII mutations and that this BMPRIB upregulation played a key role in the mitotic action of pulmonary artery smooth muscle cells in a p38MAPK-dependent manner. ${ }^{10}$ Another report also showed that experimental disruption of BMPRII leads to diminished signaling by BMP2 and BMP4 and augmented signaling by BMP6 and BMP7, suggesting gain-of-signaling mechanisms via the activation of other BMP receptor complexes. Mechanisms such as the enhancement of non-Smad-mediated ERK, JNK, p38MAPK, and LIM kinase-1 pathways, activation or inhibition of other BMP receptor complexes or TGF- $\beta$ signaling, crosstalk with other signaling molecules, and direct or indirect modification of "second hit" vascular effectors may also be involved in the underlying molecular mechanisms. .,5,11,12 $^{-1}$

The functional roles and mechanisms by which the mutations in BMPRIB initiate and promote PAH remain uncertain. As the authors point out, further investigations, such as in vitro signaling assays using human pulmonary smooth muscle cells or in vitro study using a mouse model harboring the $B M P R I B$ mutations, are necessary.

\section{Acknowledgments}

The author acknowledges the assistance of Dr Hiroko Morisaki (Department of Bioscience and Genetics, National Cerebral and Cardiovascular Center) with the manuscript.

\section{References}

1. Fukumoto Y, Shimokawa H. Recent progress in the management of pulmonary hypertension. Circ J 2011; 75: 1801-1810.

2. Simonneau G, Robbins IM, Beghetti M, Channick RN, Delcroix M, Denton CP, et al. Updated clinical classification of pulmonary hypertension. J Am Coll Cardiol 2009; 54(Suppl): S43-S54.

3. Lowery JW, de Caestecker MP. BMP signaling in vascular development and disease. Cytokine Growth Factor Rev 2010; 21: 287-298.

4. Morrell NW, Adnot S, Archer SL, Dupuis J, Jones PL, MacLean $\mathrm{MR}$, et al. Cellular and molecular basis of pulmonary arterial hypertension. J Am Coll Cardiol 2009; 54(Suppl): S20-S31.

5. Morrell NW. Pulmonary hypertension due to BMPR2 mutation: A new paradigm for tissue remodeling? Proc Am Thorac Soc 2006; 3: $680-686$.

6. Yang X, Long L, Southwood M, Rudarakanchana N, Upton PD, Jeffery TK, et al. Dysfunctional Smad signaling contributes to abnormal smooth muscle cell proliferation in familial pulmonary arterial hypertension. Circ Res 2005; 96: 1053-1063.

7. Chan Sy, Loscalzo J. Apthogenic mechanisms of pulmonary arterial hypertension. J Mol Cell Cardiol 2008; 44: 14-30.

8. Shintani M, Yagi H, Nakayama T, Saji T, Matsuoka R. A new nonsense mutation of SMAD8 associated with pulmonary arterial hypertension. J Med Genet 2009; 46: 331-337.

9. Chida A, Shintani M, Nakayama T, Furutani Y, Hayama E, Inai K, et al. Missense mutations of the BMPRIB (ALKO) gene in childhood idiopathic pulmonary arterial hypertension. Circ J 2012; 76: 1501-1508.

10. Takeda M, Otsuka F, Nakamura K, Inagaki K, Suzuki J, Miura D, et al. Characterization of the bone morphogenetic protein (BMP) system in human pulmonary arterial smooth muscle cells isolated from a sporadic case of primary pulmonary hypertension: Roles of BMP type IB receptor (activin receptor-like kinase-6) in the mitotic action. Endocrinology 2004; 145: 4344-4354.

11. Rabinovitch M. Molecular pathogenesis of pulmonary arterial hypertension. J Clin Invest 2008; 118: 2372-2379.

12. Yu PB, Deng DY, Beppu H, Hong CC, Lai C, Hoyng SA, et al. Bone morphogenetic protein (BMP) type II receptor is required for BMPmediated growth arrest and differentiation in pulmonary artery smooth muscle cells. J Biol Chem 2008; 283: 3877-3888. 